central and peripheral rotations contributed to the decision to amalgamate schemes. It would appear that, at least in terms of trainee research, this change has been a success. However, the survey also suggests that most trainees still turn first to local consultants for advice about possible research projects, and much research in Mersey is initiated anyway from the Academic Centre. Since the training schemes were amalgamated trainees have had the opportunity to rotate widely throughout the region. They are able to meet consultants with a variety of research interests who may be prepared to help them get started with their own projects. It could be this, rather than increased contact with the major teaching hospitals, which has stimulated research among the trainees in the region.

Following the 1987 survey the post of senior registrar research tutor was established, and anecdotal evidence suggests that this has been a success. A similar post for junior trainees is now being created. In view of the large number of trainees involved a single tutor would have a limited role. A major part of his or her work is expected to be in co-ordinating trainees with suitable supervisors throughout the region.

Formal teaching of research methods is currently done as a block on the MRC Psych course. Trainees have criticised the teaching, finding it difficult to relate the theory to their on-going research projects. It is hoped that in the future the course will be revised to allow for more small group discussion and experiential learning of research methods and statistics.

Trainees have been actively involved in planning changes to the course as well as in discussions about the establishment of a research tutor post.

There has not been a significant increase in the number of trainees registering for a higher degree since 1987. The MPsychMed is a thesis-based degree and, as such it is unlikely to be completed before trainees become senior registrars. With the ever increasing demand for trainees to have published work before they apply for SR posts it seems that many decide to devote their time to smaller projects which can be finished more quickly.

\section{Conclusions}

In summary, there has been a large increase in the amount of research undertaken by trainees in Merseyside since 1987. This may in part be due to the amalgamation of all training schemes in the region, which gives a chance to meet consultants with a wide range of research interests as they rotate through their jobs.

Changes that may further stimulate research are a revision of the course on research methods, and the appointment of a research tutor who will help co-ordinate the interests of trainees and supervisors around the region.

\section{Acknowledgements}

I would like to thank Dr I. A. Davidson for his helpful comments during the preparation of this paper.

\section{References}

Davidson, I. A. \& Abou-Saleh, M. T. (1987) Survey of research activity by trainees in the Mersey region. Bulletin of the Royal College of Psychiatrists, 11, 94-95.

JUNAID, O. \& DALY, R. (1991) An audit of research activity among trainee psychiatrists. Psychiatric Bulletin, 15, 353-354.

GoldBerg, D. (1991) Training in the North West (letter). Psychiatric Bulletin, 15, 775-776.

\title{
International Association of Forensic Psychiatry
}

The Second International Conference of the International Association for Forensic Psychotherapy will be held from 26-28 March 1993 at the Scientific Societies Lecture Theatre, Savile Row, London W1 with the theme Psychodynamics and the Adolescent and Female Offender. The programme will include individual, group and team based clinical and theoretical presentations by professionals working in the field. Invited speakers include: Dr R. du Bois, Mr Don Campbell, Professor Percy Cohen, Dr Jeremy Coid, Dr Christopher Cordess, Dr Murray Cox, Dr Peter Gottlieb, Dr Arthur Hyatt-Williams, the Great Ormond Street Team - Working with Female
Abusers, Dr Tim Scannell, Ms Valerie Sinason, Professor Bart de Smith, Dr Leslie Sohn, Judge Stephen Tumim, Dr Estela Welldon and other speakers from overseas. A Conference Dinner will be held at the Great Hall at St Bartholomew's Hospital Medical School. Conference fee (which includes lunches and refreshments): IAFP members $-£ 95.00$; non-members $-£ 130.00$ : Conference Dinner an additional $£ 35.00$. Further information: IAFP Secretary: Dr Tegwyn Williams, Caswell Clinic, Glanrhyd Hospital, Penyfai, Bridgend, Mid Glamorgan CF31 4LN (telephone 0656 662179). 